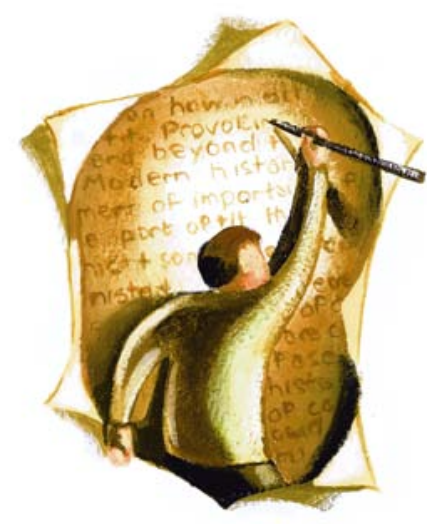

\section{Pet peeves}

My pet peeves: paper tissues in the laundry, toilet seats left up, cars that follow too closely. Dr. Ursus's pet peeve: "patients who ask to be notified of their test results."

I can understand if Dr. Ursus wants to lament the cost and inconvenience of calling patients with test results (or suggest solutions to the problem). But physicians who consider patients' health - both physical and mental - a pet peeve need to reevaluate why they are in the medical profession.

Christina M. Penner

University of Manitoba

Winnipeg, Man.

\section{REFERENCE}

I. Query. CMAJ 2006;174(9):1376.

DOI:I0.1503/cmaj.1060Io9

\section{Merits of psychotherapies}

I wish to highlight 2 issues regarding the article on the use of antidepressants in children and adolescents. ${ }^{1}$

First, the majority of the main measures used in the 16 studies failed to support the drug over placebo. Ten of these studies were unpublished (all of which were industry-sponsored) and, of these, only I study showed any significant benefit over controls. Of the 6 published studies, only 4 showed any significant benefit on main measures. On its own, this suggests a publication bias where positive studies were over 6.6 times more likely to be published than negative studies. Therefore, it is premature to conclude that these drugs are superior to placebo controls. Physicians should use great caution in making decisions based on data from published studies alone. ${ }^{2}$

Second, brief psychotherapies were not highlighted as a reasonable alternative. These treatments are non-toxic and cost-effective, and preferred by patients. ${ }^{3}$ On their own, they are more effective than wait-list or minimal treatment controls - the Treatment for Adolescents With Depression Study (TADS), cited by the authors ${ }^{1}$ is an exception. ${ }^{4}$

Given the side effects and controversies surrounding antidepressants in children, brief psychotherapies should be the first-line single treatment. ${ }^{4}$ Informed consent should include telling parents that brief psychotherapies are reasonable, safe, effective alternatives to drugs. Brief psychotherapies may improve overall coping skills and prevent relapses in children. If we lack resources to provide these treatments, parents can use this evidence to lobby government and health care providers to make sure these treatments are made available.

\section{Allan Abbass \\ Director of Education \\ Department of Psychiatry \\ Dalhousie University \\ Halifax, NS}

\section{REFERENCES}

I. Cheung AH, Emslie GJ, Mayes TL. The use of antidepressants to treat depression in children and adolescents. CMAJ 2006;174(2):193-200.

2. Melander H, Ahlqvist-Rastad J, Meijer G, et al. Evidence b(i)ased medicine - selective reporting from studies sponsored by pharmaceutical industry: review of studies in new drug applications $B M J$ 2003;326(7400):II7I-3.

3. Abbass A, Gardner D. Informed decision making with depressed patients: medications and psychotherapy options. Am Fam Physician 2004;69 (9):207I-2, 2074.

4. Ryan ND. Treatment of depression in children and adolescents. Lancet 2005;366(9498):I694.

Competing interests: None declared.

DOI:I0.I503/cmaj.I060048

\section{Privacy concerns in}

\section{preventing fraudulent}

\section{publication}

I understand the need for scientific journals to take every reasonable step to prevent the publication of flawed or fraudulent research, ${ }^{1}$ but, as Ontario's privacy commissioner, I have serious concerns about the proposed solution of publishing all of the data on which research findings are based.

The $C M A J$ editorialists state that the ethical and legal obstacles in doing so, such as "anonymizing" the data, can be overcome. However, rendering a data set anonymous is not a trivial matter. My experience in dealing with privacy issues in the context of research indicates little consensus within the research community as to what variables need to be stripped from a data set to render it truly anonymous. If anonymization is not done in an extremely conservative manner, the data set could be used alone or linked with other data to re-identify individuals. There is also the risk of re-identification of individuals through the publication of small sets of data.

It is my understanding that most researchers treat all data sets anonymized or not - as confidential personal information, a highly desirable practice. Further, to the extent that anonymous data sets may be used to reidentify individuals, their publication may be a violation of Ontario's Personal Health Information Protection Act (PHIPA) (and possibly other health privacy statutes in other provinces) and/or the requirements imposed by research ethics boards.

Even if data sets could be truly anonymized, it is not clear that their publication would be useful for validating research, as suggested in the editorial. ${ }^{1}$ In many cases, there would be insufficient information in a stripped-down data set to replicate findings or conduct further analyses.

The publication of data sets would 
pose a serious threat to the privacy of individual research subjects. In the absence of clear evidence that the publication of anonymized data sets would deter the publication of flawed or fraudulent research, and in the absence of a clear standard for anonymizing data sets to ensure that individuals cannot be re-identified, alternative means of validating research findings should be considered.

\section{Ann Cavoukian}

Information and Privacy

Commissioner of Ontario

Toronto, Ont.

\section{REFERENCE}

I. Are journals doing enough to prevent fraudulent publication? [editorial]. CMAJ 2006;174(4):431.

DOI:Io.I503/cmaj.106008o

\section{One country, too many}

\section{licensing bodies}

Having worked in the medical profession in both Canada and abroad, I have come to the conclusion that Canada, the second-largest country in the world (in geographic terms), is too small to have separate medical licensing boards for each province and territory.

Let me explain. Prospective medical students in Canada compete for all the first-year medical school slots across Canada. Of those accepted, the vast majority finish medical school by writing the examinations for the Licentiate of the Medical Council of Canada (LMCC). They then compete for the available internship positions, and many go on to do advanced training, eventually writing the Canada-wide examinations of the Royal College of Physicians and Surgeons of Canada (RCPSC).

The net result is a pool of hundreds, perhaps thousands, of highly qualified Canadian physicians who might like to practise or do locums in some of the more remote areas of our vast country. But they have to get a licence for each province or territory where they might want to do a locum.

One country, one LMCC credential, one RCPSC, and one Canadian Medical Protective Association (CMPA), but I3 licensing bodies (colleges) - it's time to clean up our act.

Here is my proposal. If a physician has a valid medical licence to practise in any province or territory of Canada, along with a clean bill of conduct and CMPA coverage, he or she should be allowed to do locums anywhere in Canada without further licensing requirements.

\section{Stephen Sullivan \\ Victoria, BC}

DOI:I0.1503/cmaj.ro60o8I

\section{The problem of evidence-}

\section{based medicine in}

\section{developing countries}

In a recent article, Caleb Alexander and associates $^{1}$ elucidate the issue of prioritizing and stopping prescription medicines, pointing to a lack of data on the safety and optimal means of discontinuing drugs. ${ }^{1}$ This may be the core problem in developed countries, but the situation is altogether different in developing countries, where a poor research culture is the biggest obstacle to the promotion of evidence-based medicine and in turn to the prioritization and discontinuation of prescription medicines.

The utilization and production of research, along with human and institutional development, are 2 important components of health research. ${ }^{2}$ Without these, it is very difficult to practise evidence-based medicine.

The utilization of research, which is the backbone of evidence-based medicine, is in a terrible state in developing countries. A recent study conducted in a hospital in Pakistan found that only $20 \%$ of residents read medical journals monthly, only $\mathrm{I} 2 \%$ had ever written for medical journal publication, and $12 \%$ had never read a medical journal. ${ }^{3}$

The state of the production of research is also not encouraging. In all disciplines of science and technology, India and Pakistan combined have 208 researchers per million citizens; the comparable figure for the United States is 4526 researchers per million. ${ }^{4}$
By highlighting this issue of poor research culture, we hope to contribute to increased awareness among those who read journals and who can bring about positive change.

\section{Ahmad A. Sabri \\ Physician \\ Faisalabad, Pakistan \\ Muhammad Ahad Qayyum \\ Physician \\ Mayo Hospital Lahore \\ Lahore, Pakistan}

\section{REFERENCES}

I. Alexander GC, Sayla MA, Holmes HM, et al. Prioritizing and stopping prescription medicines. CMAJ 2006;174:1083-4.

2. Sadana R, D'Souza C, Hyder AA, et al. Importance of health research in South Asia. BMJ 2004; 328:826-30.

3. Aslam F, Qayyum MA, Mahmud H, et al. Attitudes and practices of post graduate medical trainees towards research - a snapshot from Faisalabad. J Pak Med Assoc 2004;54:534-6.

4. Aslam F, Shakir M, Qayyum MA. Why medical students are crucial to the future of research in South Asia. PLoS Med 2005;2(II):e322.

DOI:I0.I503/cmaj.Io6oro8

\section{Private health insurance}

\section{needs consent}

Loreen Pindera ${ }^{1}$ describes the Quebec health ministry's recently released white paper, which recommends private health insurance as a means of reducing waiting time for "elective hip, knee and cataract surgeries, and to cancer-related surgeries." ${ }^{2}$ According to the white paper, "This is the first step: the mechanism could be extended to other types of hospital services...."

However, the Romanow Commission "heard from Canadians through the Citizens' Dialogue and other consultations [that] the large majority of Canadians do not want to see change in the single-payer insurance principle for core hospital and physician services." 3 Given this evidence of citizens' resistance to changes such as those proposed for Quebec and to ensure respect for the autonomous choices and preferences of Quebeckers, it seems to me that any proposed changes in hospital and physician care must have explicit "informed consent" from the public.

Moreover, the method of consulta- 